committee to help visiting scientific expeditions in all matters of transport, meteorology, health conditions and camp installation. The Dean of the Faculty, Prof. Godofrich Garcia, is president of the Committee.

So far, three expeditions have been announced as going to observe this eclipse. With the aid of a sloop of the New Zealand Navy, Mr. C. B. Michie, of Kaitaia, N.Z., is taking a party consisting of Dr. W. C. Burns and Mr. F. Gawithall three being members of the 1930 expedition to Niaufou' or Tin-can Island-and Mr. Thomsen and some other member of the staff of the Dominion Observatory. The 19-foot coronagraph used at the eclipses of 1926, 1929, 1930, 1932, and 1936, has been sent to Mr. Michie from Japan and will be taken by him to Canton Island. By kind permission of the Royal Irish Academy, the 8-inch Grubb cœlostat will be used to feed the coronagraph. Photographs of the corona will, it is hoped, be secured through various colour-filters. Other details of the programme are not available here. Another party will be organized by the U.S. Nary, the National Geographic Society and the National Bureau of Standards, and will proceed to Canton or Enderbury Island. Prof. S. A. Mitchell, director of the Leander McCormick Observatory, will be the scientific leader of the expedition, while Captain J. F. Hellweg, Superintendent of the U.S. Naval Observatory, Washington, will be responsible for the naval side of the work. Dr. H. D. Curtis, director of the Ann Arbor Observatory, Michigan, Dr. P. A. McNally, director of the Georgetown College Observatory, Dr. F. K. Richtmyer, of Cornell University, Dr. I. C. Gardner, National Bureau of Standards and Mr. J. W. Willis, of the Naval Observatory, accompany the expedition and assure a wealth of valuable eclipse experience. The party will be completed by a naturalist (a naval surgeon), and a photographer from the National Geographic Society.

The spectrum of the chromosphere and corona will be photographed by Dr. Mitchell and Dr. Curtis respectively. Dr. MeNally will photograph the corona through a variety of filters, while Dr. Richtmyer will measure the total light of the corona. Colour photographs of the corona will be attempted by Dr. Gardner, who will repeat some of the photographs secured by him in Siberia last June (see Nature, March 13, p. 434). Time observations of contacts will be made by the observers from the Naval Observatory.

This party will be taken from Honolulu by the U.S. Navy mine-sweeper Avocet early in May. They may have a difficult time in preparing for the eclipse. We can only hope that the good weather, which has generally, though not invariably, attended Dr. Mitchell and Dr. Curtis, will hold for both parties on the morning of June 8 next.

A Japanese expedition, under the leadership of Prof. I. Yamamoto, of the Kwasan Observatory, Kyoto, will proceed to the coast of Peru to observe the eclipse of next June at sunset. The other members of the party are Prof. T. Araki and Messrs. Y. Sibata and M. Horii. The programme includes photography of the corona and of the spectra of the chromosphere and corona, photometry of the corona and some geodetic observations. The equipment will include some cinematograph cameras.

\title{
Radium Treatment in Great Britain
}

$\mathrm{R}^{2}$ ADIUM treatment is an established medical service in Great Britain, as may be gathered from the reports which are issued from year to year, especially by the four important organizations which have the responsibility of encouraging its practice and of helping research bearing upon its many problems. These organizations are the National Radium Commission, now in its eighth year of existence, and King Edward's Hospital Fund for London, both of which are primarily concerned with treatment; the British Empire Cancer Campaign and the Medical Research Council, whose interests in the subject are primarily research, their common matters of discussion in the first instance usually being referred to a joint
Radiology Committee. The allocation of radium by these four organizations at present exceeds 40 grams of radium element.

The seventh annual report of the Radium Commission* includes a statistical report of 47 pages which teems with interest. It being no longer a question whether radium is of any use in the treatment of cancer, one of the first questions which the Commission has tried to answer is how much use it is. To this end, an elaborate plan was laid, and the first fruits of this are now at hand. The present report gives the 3-year and 5-year results of radium treatment of five common

* Seventh Annual Reports of the National Radium Trust and Radium Commission 1935-1936 including a Statistical Report. (Cmd. 5342.) Pp. 91. (London: H.M. Stationery Office, 1937.) 18. 6d. net. 
sites of cancer, namely, breast, cervix uteri, lip, tongue and floor of mouth. From the data contained in thirty-nine tables it is now possible to obtain the answer to almost any question that can normally arise concerning the probable results of treatment, as practised throughout the country. The report is based upon an analysis of the records of more than 5,600 patients, and the hospitals from which the patients have been drawn are widely distributed throughout the whole of Great Britain.

Little is said throughout this statistical report of the efforts which the Radium Commission made in its preparation of suitable clinical record sheets and statistical cards so as to ensure that the right kind of information was eventually received from its National and Regional Centres, preferring to report upon the fact that the accuracy of this material has shown signs of steady improvement. How loyally these Centres have contributed in the work of the follow-up of patients is shown by the fact that only 3.9 per cent of the total patients has been lost sight of.

The spirit of co-operation is further shown by the arrangement made by the authorities of King Edward's Hospital Fund, that the data from hospitals receiving allocations of radium from the Fund should be put at the service of the Commission.

Though radium is used in the treatment of other diseases, its outstanding medical interest is its use in cancer, and one of the chief difficulties in the preparation of data is to agree upon some common and acceptable method of classifying the various stages of the disease. This had already been done in 1929 for uterine cancer by the Radiological Sub-Commission of the League of Nations Health Organization, but for no other sites. The Commission therefore undertook this for the other sites of cancer already mentioned.

The general scheme of the report follows the same lines for each site under investigation; the completeness of the information may be gathered from the following tabular headings : percentage net survival rates; patients who have died classified according to cause of death; percentage three-year net survival rate according to whether or not a histological examination was made; number of patients treated by different methods or combinations of methods ; percentage net survival and symptom-free rates at three and five years after treatment according to method of treatment and stage of disease; age distribution of patients ; three-year net survival rate according to age of patient and stage of treatment.

In only one of the five groups, namely, carcinoma of the cervix uteri, is there any appreciable difference in the three-year net survival rate according to whether or not a histological examina. tion was made. Table 13 is here reproduced; while no explanation is available, it may be suggested that the failure to have this valuable histological evidence was only one indication of inadequate trea tment.

Table 13. Carcinoma of Cervix.

Percentage three-year net survival rate according to whether or not a histological examination was made.

\begin{tabular}{|c|c|c|c|c|c|}
\hline \multicolumn{4}{|c|}{$\begin{array}{l}\text { Stage of } \\
\text { Disease }\end{array}$} & \multirow{2}{*}{ 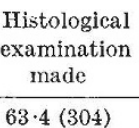 } & $\begin{array}{l}\text { No histological } \\
\text { examination }\end{array}$ \\
\hline I & .. & .. & .. & & $50 \cdot 8 \quad(66)$ \\
\hline II & . & .. & . & $51 \cdot 2(440)$ & $35 \cdot 7 \quad(99)$ \\
\hline III & . & . & . & $32 \cdot 4(678)$ & $15 \cdot 5(120)$ \\
\hline IV & . & $\cdots$ & . & $15 \cdot 0(266)$ & $5.0 \quad(85)$ \\
\hline \multicolumn{2}{|c|}{ All stages } & .. & . & $40 \cdot 0(1,688)$ & $24 \cdot 8(370)$ \\
\hline
\end{tabular}

Numbers in brackets are the number of patients.

The dangers of malignant disease are twofold; primarily the growth with its local spread, secondarily its extension into other structures of the body. The extent to which the latter adds to the difficulty of radiological treatment is well shown in the section of the report devoted to carcinoma of the tongue. The patients were classified according to the stage of the disease as follows :

I. Primary growth limited to the tongue: (a) glands not involved; (b) glands involved.

II. Primary growth limited to the tongue and floor of mouth : $(a)$ glands not involved ; $(b)$ glands involved.

III. Primary growth has spread from the tongue to other structures within the mouth : (a) glands not involved; $(b)$ glands involved.

This should be read in conjunction with the following data contained in Table 27.

Table 27. CARcinoma of the Tongue.

Percentage net survival rates from all methods of treatment in which radium was employed.

\begin{tabular}{|c|c|c|c|c|c|}
\hline \multirow{2}{*}{\multicolumn{4}{|c|}{$\begin{array}{l}\text { Stage of } \\
\text { Disease }\end{array}$}} & \multicolumn{2}{|c|}{ Net Survival Rate at: } \\
\hline & & & & \multirow{2}{*}{$\frac{3 \text { years }}{49 \cdot 7(339)}$} & \multirow{2}{*}{$\frac{5 \text { years }}{26 \cdot 2(83)}$} \\
\hline Ia & .. & .. & .. & & \\
\hline $\mathrm{Ib}$ & $\ldots$ & $\cdots$ & $\cdots$ & $12 \cdot 6(310)$ & $5 \cdot 1(85)$ \\
\hline IIa & .. & $\ldots$ & . & $39 \cdot 6(143)$ & $18 \cdot 5(29)$ \\
\hline IIb & .. & . & .. & $11 \cdot 5(265)$ & $11 \cdot 1(57)$ \\
\hline IIIra & .. & . & . & $31 \cdot 0 \quad(47)$ & $-\quad(6)$ \\
\hline IIIb & .. & . & . & $7 \cdot 5(136)$ & $3 \cdot 3(30)$ \\
\hline \multicolumn{2}{|c|}{ All stages } & . & . & $25 \cdot 7(1,240)$ & $13 \cdot 9(290)$ \\
\hline
\end{tabular}

For those who prefer composite figures, the following data (p. 701) are available, giving net survival rates in percentages.

The impression should not be formed that these patients have been treated by means of radium only; this is far from the case. In breast cancer, for example, no less than 86 different conbinations of methods of treatment come under analysis, 
in uterine cancer 66 , and so on. This arises from the fact that there are three main methods in radium treatment, each of which may be associated with varied surgical or X-ray treatment.

\begin{tabular}{|c|c|c|c|c|c|}
\hline \multirow{2}{*}{\multicolumn{2}{|c|}{ Site }} & \multicolumn{2}{|c|}{$\begin{array}{c}\text { Earliest Stage } \\
\text { of Disease }\end{array}$} & \multicolumn{2}{|c|}{$\begin{array}{c}\text { All Stages of } \\
\text { Disease }\end{array}$} \\
\hline & & 3 years & 5 years & 3 years & 5 years \\
\hline Breast $\quad \ldots$ & .. & $70 \cdot 1$ & $50 \cdot 0$ & $37 \cdot 2$ & $24 \cdot 6$ \\
\hline Cervix Uteri & .. & $61 \cdot 1$ & $49 \cdot 4$ & $37 \cdot 3$ & $31 \cdot 1$ \\
\hline Lip $\quad$. . & .. & $77 \cdot 5$ & $77 \cdot 8^{*}$ & $63 \cdot 8$ & $53 \cdot 6$ \\
\hline Tongue $\quad \ldots$ & . & $49 \cdot 7$ & $26 \cdot 2$ & $25 \cdot 7$ & $13 \cdot 9$ \\
\hline Floor of Mouth & . & $62 \cdot 0$ & $53 \cdot 6$ & $36 \cdot 2$ & $31 \cdot 0$ \\
\hline
\end{tabular}

* Small group of patients.

Difficulties in treatment are many, but no sentence in this report brings these difficulties more acutely to mind than the following:

"The proportion of patients in whom the disease is still localised to its original site and in whom there are no signs of local or metastatic spread when the patient is first seen amount, for all sites investigated, to only 25 per cent. of the patients. The marked difference in the survival rates shows that for these patients the chances of survival are much more favourable than when either local spread or metastasis has taken place."

Of necessity the results of individual centres cannot be gauged when merged into the larger groups, so invaluable for statistical work. From the reports entitled "Medical Uses of Radium" issued for the last fifteen years by the Medical Research Council, this can be done for the centres taking part in its scheme of research. These reports also from time to time show the important results of radium treatment in certain non-malig. nant gynæcological conditions.

Radium has proved of service in the treatment of cancer, especially when the direction of the medical services has been in competent and inspiring hands. The tendency in treatment is for less interstitial work to be done, giving way to surface and distant applications of radium, the latter involving the use of bigger units, 1-5 grams. There is little doubt that, as the warrant is shown for the use of these bigger units, the country will see to it that the necessary radium is provided.

S. Russ.

\section{Centenary of the University of Göttingen}

\section{From a Correspondent}

G ÖTTINGEN is celebrating its bicentenary on June 30 of this year. Perhaps no university has maintained so high a standard of learning over so long a period as Göttingen. Among its illustrious professors have been Albrecht von Haller, a man of most varied genius and the first modern physiologist, Gauss, supreme alike as mathematician, astronomer and experimenter, Blumenbach, the humane and wise father of anthropology, the brothers Grimm, begetters of modern scientific philology, whose name is known in every nursery, Wilhelm Weber, associated with the measurement of electrical quantities, with terrestrial magnetism, with the electric telegraph and, along with his brother Ernst, with a multitude of physiological researchers, Ewald, the Hebrew scholar, commonly regarded as the father of scientific biblical criticism, Wüstenfeld, who traced the debt that European science owes to the Arabic-speaking world, and Henle, one of the greatest of anatomists, founder of the science of histology, whose name is attached to more than one structure of the body. These men and their colleagues and successors taught and inspired innumerable English-speaking students.
During the first third of the twentieth century, Göttingen fully maintained its historic standards. Its mathematical disciplines, especially, were held in the highest esteem. The great mathematicalphysical group at Göttingen was, beyond all cavil, the most important scientific school in post-War Germany. Members of this school were among the first to re-establish contact with English colleagues after the War, and Göttingen was the first German university to receive English students.

The University of Göttingen was founded by George II of England, and opened on October 31, 1734. Thus an appropriate occasion for a bicentenary would have been the early autumn of 1934. At that time, however, both Germany and her neighbours were still very conscious of the effects of the official massacre, known as the 'clean-up', of June 30 of that year. The number who perished on that day is still not exactly known-the German Government has published no list-but a list of persons of political importance who disappeared about that time contains no less than 1,184 names. Further, it was towards the end of June 1933 that students and "black guards" (S.S. men) secured a great number of books from 